\title{
MERUMUSKAN DAN MENGEMBANGKAN PERENCANAAN PEMASARAN UKM KERIPIK PISANG KHARISMA
}

\author{
Asvinanto F
}

Untuk mempertajam dan memperdalam pemahaman tentang konsep dan strategi perencanaan pemasaran suatu bisnis atau produk, survey atau observasi lapangan kepada pelaku bisnis kecil dapat digunakan dalam proses pembelajaran, dengan harapan fakta operasional bisnis kecil dalam merencanakan dan mengembangkan bisnis dapat tergambar dengan jelas.

Berikut ini adalah Panduan singkat untuk melakukan Observasi lapangan tersebut:

Setiap Mahasiswa melakukan survey dan wawancara kepada 1 (satu) orang pelaku bisnis kecil dan menengah (UKM) yang operasionalisasinya masih dijalankan.

Hal-hal yang perlu ditanyakan saat wawancara adalah :

1. Produk apa yang dijual

2. Berapa Harga jual produk

3. Bentuk Promosi apa yang dilakukan (contoh: potongan harga bagi pelanggan, menghias booth/gerobak tempat berjualannya, dsb)

4. Bentuk pendistribusian yang dilakukan. (contoh: layanan antar ke tempat pemesan)

Berdasarkan hasil wawancara tersebut, buatlah usulan perencanaan pemasaran terkait :

a. Perencanaan Pemasaran Pengembangan Produk yang dijual UKM tersebut (contoh: inovasi produk, kemasan). Orientasikan produk dijual secara online

b. Perencanaan Pemasaran Penetapan Harga jual produk tersebut (contoh: menggunakan penetration pricing yang dihubungkan dengan daur hidup produk)

c. Perencanaan Pemasaran bentuk promosi yang tepat dilakukan UKM tersebut (contoh: menggunakan media sosial, dengan tetap memperhatikan karakteristik produknya)

d. Perencanaan pemasaran penggunaan saluran distribusi agar konsumen dapat mengakses produk tersebut (Contoh: menyediakan layanan pesan-antar)

Hasil wawancara dan rumusan perencanaan pemasaran ditulis rapi menggunakan Ms Word, lalu di-submit ke dalam sistem elearning UT disertai dengan Gambar/Photo UKM-nya. 
wawancara dilakukan dengan pemilik usaha Keripik Pisang Kharisma yang menjual keripik pisang dengan lima varian rasa yaitu original, manis, cokelat, balado, dan cappuccino.

Harga jual produk saat ini sebesar Rp 25.000 per kemasan 250 gram.

Bentuk promosi yang dilakukan yaitu melalui media online serta adanya diskon setiap pembelian 10 bungkus disertai gratis 1 bungkus.

Selain penjualan di toko milik sendiri, bentuk distribusi yang dilakukan yaitu dengan menggunakan reseller serta berjualan via e-commerce. Bisa juga dipesan untuk diantar langsung melalui ojek online.
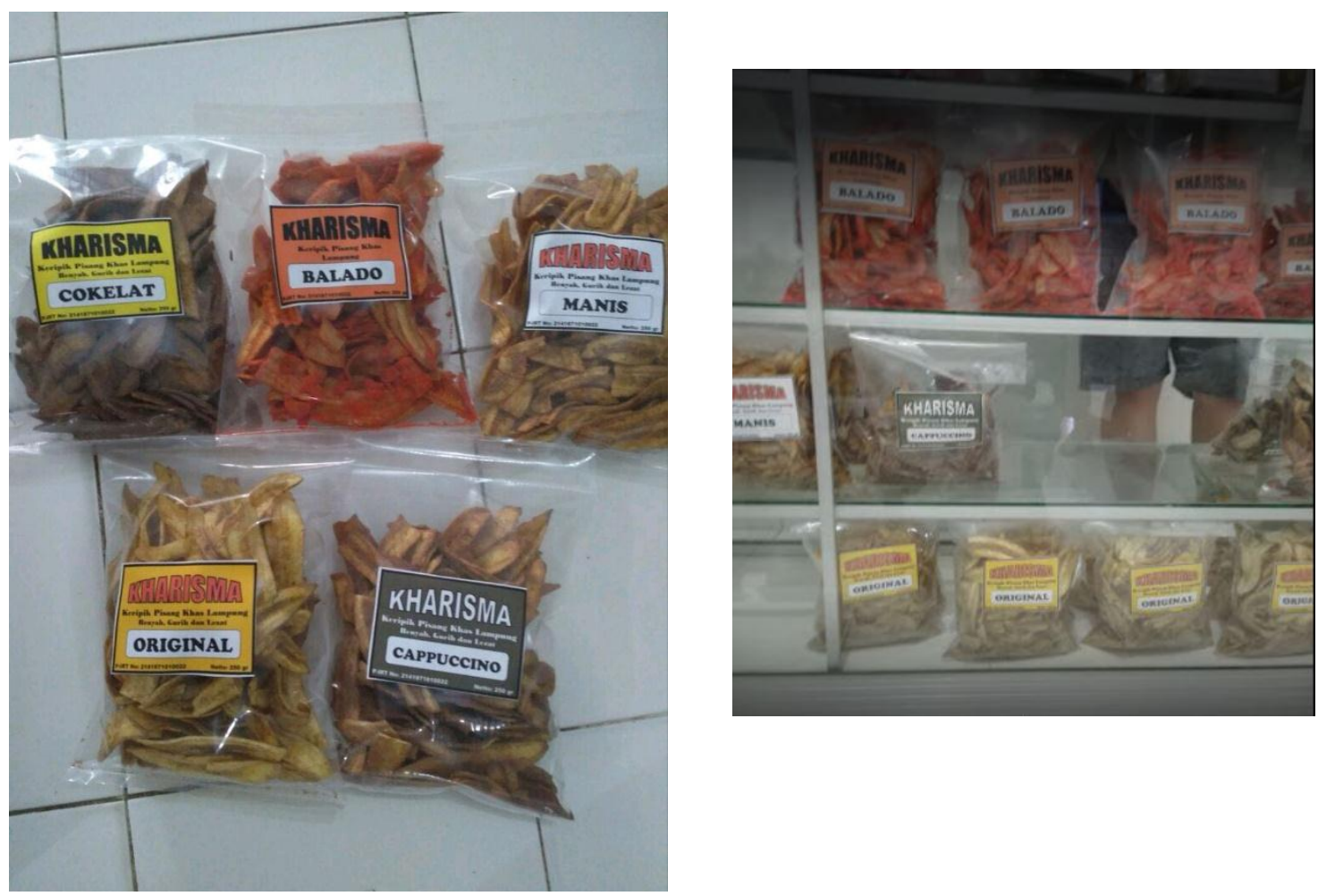

Rencana Pemasaran :

a. Kemasannya harus dikemas secara lebih modern agar tampak menarik. Keripik ini rasanya enak dan tidak kalah dengan pesaingnya seperti keripik Aneka atau Iyen. Namun hal yang membuat keripik ini tidak menarik adalah kemasannya bila dibandingkan dengan pesaingnya. 

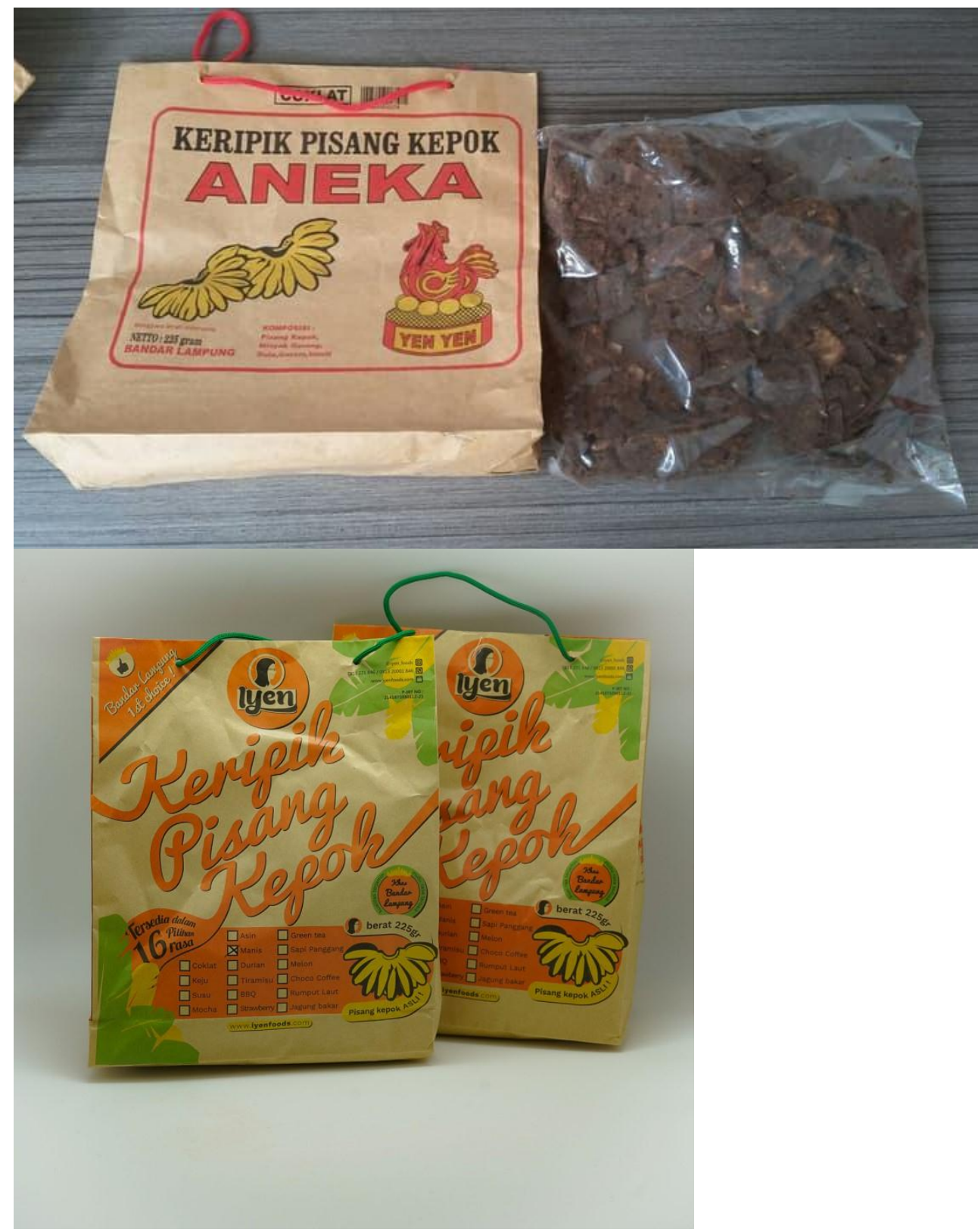

b. Bisnis keripik pisang di Lampung saat ini dikuasai oleh 2 merek, yaitu Aneka dan Iyen. Harga untuk merek Kharisma bisa dibilang bersaing dengan 2 merek tersebut. Harga saat ini sudah tepat untuk penetrasi pasar pada siklus produk saat ini. Lakukan promosi secara gencar untuk bisa menjangkau pasar lebih luas.

c. Promosi melalui media sosial harus terus dilakukan. Lakukan juga penjualan langsung dengan menghadiri tempat ramai, misalnya saat car free day atau di pusat kegiatan masyarakat seperti lapangan kota atau alun alun supaya banyak calon konsumen yang sadar akan keberadaan produk. Berikan juga free sample supaya konsumen bisa menilai langsung produk.

d. Saluran distribusi yang ada saat ini pun sudah tepat dengan adanya reseller serta penjualan melalui e-commerce dan terdaftar di layanan pesan makanan ojek online. Promosi yang gencar adalah kunci untuk memperluas saluran distribusi ini. 
Referensi :

Mulyana, M., Hidayat, L., \& Puspitasari, R. (2019). Mengukur Pengetahuan Investasi Para Mahasiswa Untuk Pengembangan Galeri Investasi Perguruan Tinggi. JAS-PT (Jurnal Analisis Sistem Pendidikan Tinggi Indonesia), 3(1), 31-52.

Binangkitsari, L. (2018). The Influence of Brand Equity Elements on Purchase Decision and Its Imlication on Customer Loyalty.

Sulistiono, S., \& Bawono, S. (2009). Membangun Strategi Promosi Dalam Pengembangan Bisnis. Jurnal Ilmiah Kesatuan (JIK), 11(2).

Munawar, A., \& Purba, J. H. V. (2006). Kajian Dampak Pelatihan terhadap Kinerja Karyawan. Jurnal Ilmiah Kesatuan Nomor, 8(7), 2.

Munawar, A., \& Marpaung, B. S. (2013). Pengaruh Arus Kas Operasi Terhadap Peningkatan Kemampulabaan dan Pertumbuhan Perusahaan. Jurnal Ilmiah Manajemen Kesatuan, 1(3).

Pamungkas, B., \& Mustikawati, D. S. (2015). Analisis Penerapan PSAK 45 (Revisi 2011) Terhadap Penyusunan Laporan Keuangan Entitas Nirlaba (Studi Kasus pada Yayasan Dharma Setia Kosgoro). Jurnal Ilmiah Akuntansi Kesatuan, 3(2), 101-110.

Fadillah, A., Sujana, S., \& Sukartaatmadja, I. (2019). Kajian Minat Studi Lanjut Siswa-Siswi SMA dan SMK Kota Bogor Ke Perguruan Tinggi. JAS-PT (Jurnal Analisis Sistem Pendidikan Tinggi Indonesia), 3(1), 53-62.

Pauziah, P., \& Mulyana, M. (2018). Formulation of The Green Marketing Development Strategy for the Body Shop Botani Square Bogor. In THE INTERNATIONAL CONFERENCE ON ACCOUNTING AND MANAGEMENT SCIENCE (p. 171).

Maulana, M. A., Iriyadi, I., \& Nurjanah, Y. (2018). Financial Reporting for Micro Small and Medium Enterprises Towards Industrial Revolution Era 4.0. In THE INTERNATIONAL CONFERENCE ON ACCOUNTING AND MANAGEMENT SCIENCE (p. 32-38). 